\title{
Participação do Complexo Amigdalóide nA Resposta DE CONGELAMENTO EM RATOS GENETICAMENTE SELECIONADOS
}

Vitor de Castro Gomes

Linhagens de animais são bastante usadas para investigar as bases genéticas de várias desordens psiquiátricas. Nosso laboratório vem desenvolvendo uma linhagem em ratos para reagirem com alta (HCF - High Conditional Freezing) ou baixa (LCF - Low Conditional Freezing) resposta condicionada de congelamento a estímulos contextuais previamente associados a choques elétricos. O presente trabalho teve como objetivo investigar os efeitos comportamentais de lesões eletrolíticas no complexo amigdalóide destes ratos geneticamente selecionados.

\section{BANCA:}

Jesus Landeira Fernandez (Orientador)

André de Ávila Ramos

Guilherme Gutman Correa de Araujo

Data de defesa: 5/10/2007 